\title{
Umbilical vein injection of misoprostol versus normal saline for the treatment of retained placenta: intrapartum placebo-controlled trial
}

\author{
Sheelan S Rajab ${ }^{1}$ and Shahla K Alalaf ${ }^{2^{*}}$
}

\begin{abstract}
Background: The third stage of labour may be complicated by retained placenta, which should be managed promptly because it may cause severe bleeding and infection, with a potentially fatal outcome. This study evaluated the effectiveness of umbilical vein injection of misoprostol for the treatment of retained placenta in a hospital setting.
\end{abstract}

Methods: This hospital-based placebo-controlled trial was conducted at the Maternity Teaching Hospital, Erbil City, Kurdistan region, Northern Iraq from April 2011 to February 2012. The inclusion criteria were: gestational age of at least 28 weeks, vaginal delivery, and failure of the placenta to separate within 30 minutes after delivery of the infant despite active management of the third stage of labour. Forty-six women with retained placentas were eligible for inclusion. After informed consent was obtained, the women were alternately allocated to receive umbilical vein injection of either $800 \mathrm{mcg}$ misoprostol dissolved in $20 \mathrm{~mL}$ of normal saline (misoprostol group) or $20 \mathrm{~mL}$ of normal saline only (saline group). The women were blinded to the group allocation, but the investigator who administered the injection was not. The trial was registered by the Research Ethics Committee of Hawler Medical University.

Results: After umbilical vein injection, delivery of the placenta occurred in $91.3 \%$ of women in the misoprostol group and $69.5 \%$ of women in the saline group, which was not a significant difference between the two groups. The median vaginal blood loss from the time of injection until delivery of the placenta was significantly less in the misoprostol group $(100 \mathrm{~mL})$ than in the saline group $(210 \mathrm{~mL})(p$ value $<0.001)$.

Conclusion: Umbilical vein injection of misoprostol is an effective treatment for retained placenta, and reduces the volume of vaginal blood loss with few adverse effects.

Clinical Trial Registration: Current Controlled Trial HMU: N252.1.2011

Keywords: Intraumbilical misoprostol, Retained placenta, Active management of third stage of labour

\section{Background}

Definitions and maternal complications of retained placenta

No consensus exists regarding the normal length of the third stage of labour, or the time at which the placenta should be termed "retained" and intervention should be started [1].

\footnotetext{
*Correspondence: shahla_alaf@yahoo.com

${ }^{2}$ Department of Obstetrics and Gynaecology, College of Medicine,

Hawler Medical University, Erbil City, Iraq

Full list of author information is available at the end of the article
}

The intrapartum guidelines published by the National Institute for Health and Clinical Excellence suggest intervention when the placenta has not been delivered within 30 minutes after birth with active management of the third stage of labour, or within 60 minutes after birth with physiological management of the third stage of labour [2].

Complications of RP include shock, postpartum haemorrhage, puerperal sepsis, and uterine subinvolution; which may result in the patient requiring hysterectomy [3].

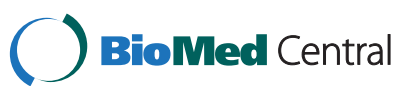

(c) 2014 Rajab and Alalaf; licensee BioMed Central Ltd. This is an open access article distributed under the terms of the Creative Commons Attribution License (http://creativecommons.org/licenses/by/2.0), which permits unrestricted use, distribution, and reproduction in any medium, provided the original work is properly cited. 
In 1993, Herman first demonstrated ultrasonographically that retroplacental myometrial contraction is necessary to produce the shearing forces to the interface between the placenta and the myometrium that result in detachment of the placenta [4].

The current standard of management for RP is manual removal of the placenta (MROP), which usually requires general or regional anaesthesia at a hospital. MROP is an invasive procedure that may lead to serious complications such as haemorrhage, infection, and genital tract trauma. A simple and safe treatment for RP that can be administered at the location of the birth and reduces the need for MROP could be of major benefit to women worldwide [5].

\section{Administration of uterotonic drugs via the umbilical vein}

The World Health Organization recommends umbilical vein injection of a uterotonic drug as the first line of treatment for RP. However, this treatment is not routinely used, probably because of lack of a large randomized controlled trial, and uncertainties regarding optimal drug and dosage regimens [6]. A Cochrane collaboration review found that umbilical vein injection of oxytocin is not effective for the treatment of RP [7]. A double-blind, placebo-controlled trial including women in the UK, Uganda, and Pakistan reported that umbilical vein injection of oxytocin had no clinically significant effect on the need for MROP [8].

\section{Study justification}

All women should have access to simple and non invasive treatment for RP, whether delivering in a wellequipped hospital or a low-resource setting. To our knowledge, this is the first study of the effectiveness of umbilical vein injection of misoprostol for the treatment of RP to be conducted at a large maternity hospital. The Maternity Teaching Hospital is the only public hospital in Erbil City that manages high-risk pregnancies and deliveries. Most local women who develop complications after giving birth at home are treated at this hospital. The results of preliminary published trials suggest that administration of prostaglandins such as misoprostol may result in delivery of the placenta and reduced volume of blood loss in women with RP. This study evaluated the effectiveness of umbilical vein injection of misoprostol dissolved in normal saline versus normal saline only for the treatment of RP.

\section{Aims}

The aims of this study were: (1) to determine whether umbilical vein injection of misoprostol for the treatment of RP reduces the need for MROP, and (2) to compare the volume of vaginal blood loss between women with
RP who received umbilical vein injection of misoprostol and those who received normal saline only.

\section{Hypothesis}

The primary hypothesis was that umbilical vein injection of misoprostol in women with RP despite active management of labour reduces the need for MROP under general anaesthesia. The secondary hypothesis was that umbilical vein injection of misoprostol in women with $\mathrm{RP}$ reduces the volume of vaginal blood loss.

\section{Methods}

\section{Design and setting}

This was a hospital-based, placebo-controlled clinical trial conducted at the Maternity Teaching Hospital in Erbil City, Northern Iraq from April 2011 to February 2012, including data collection and entering, follow-up of women, data analysis, and writing of the manuscript.

The Maternity Teaching Hospital is the only public maternity hospital in Erbil. This hospital provides obstetric services including management of high-risk pregnancies, medical terminations of pregnancy, and management of high-risk deliveries including caesarean deliveries. The hospital serves the entire population of the Erbil governorate, and is equipped to cope with emergency procedures 24 hours a day. The Directorate of Health in Erbil City reported 22,387 deliveries at the hospital during 2008, with an institutional delivery rate of $53.6 \%$.

\section{Inclusion and exclusion criteria}

All women with a singleton pregnancy who delivered vaginally after at least 28 weeks of gestation and had a prolonged third stage of labour (more than 30 minutes) despite active management (intramuscular administration of $5 \mathrm{IU}$ oxytocin and controlled cord traction) were considered to have RP, and were eligible for inclusion in the study unless they had significant bleeding. The exclusion criteria were: multiple pregnancies, previous caesarean delivery, haemodynamic instability, severe anaemia (haemoglobin concentration $<8 \mathrm{~g} / \mathrm{dL}$ ), chorioamnionitis, and refusal of consent for inclusion (Figure 1).

\section{Enrolment, sample size, and group allocation}

Routine management at the Maternity Teaching Hospital includes active management of the third stage of labour. Eligible women were identified when the placenta was not delivered within 30 minutes after delivery of the infant.

Informed consent was obtained from all subjects after explanation of the study protocol. The study was approved and registered by the Research Ethics Committee and Scientific Committee of the College of Medicine, Hawler Medical University (N252.1.2011). 


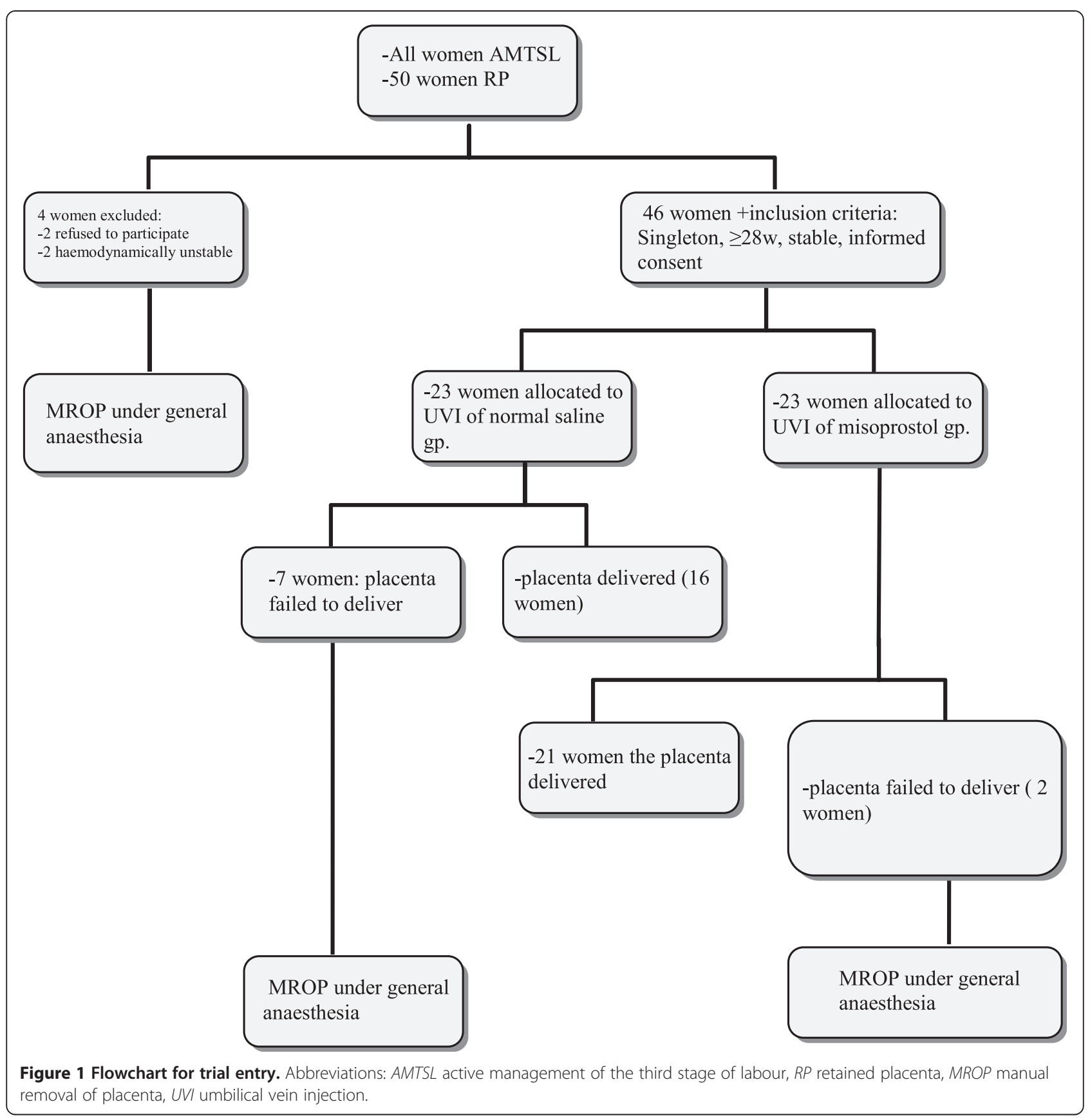

Two syringes were prepared every day: one containing misoprostol dissolved in $20 \mathrm{~mL}$ of normal saline and the other containing $20 \mathrm{~mL}$ of normal saline only.

Women were alternately allocated to receive umbilical vein injection of either misoprostol in normal saline (misoprostol group) or normal saline only (saline group). The women were blinded to the group allocation, but the investigator who administered the injection was not. Data were collected using a specially designed questionnaire, including the obstetric history, general examination findings, vital signs, obstetric and vaginal examination findings, and haemoglobin concentration.

\section{Umbilical vein injection technique}

Umbilical vein injection was performed according to the Piping's method, as follows. The cord was cut, and a size 10 paediatric nasogastric tube was advanced into the umbilical vein. If resistance was felt, the catheter was retracted $1-2 \mathrm{~cm}$ and then advanced further if possible. If the catheter could not be advanced further without 
using force, the injection was administered through the catheter at that time. If the majority of the catheter was inserted before resistance was felt, indicating that it had reached the placenta, the catheter was retracted $3-4 \mathrm{~cm}$ to ensure that the tip was in the umbilical vein and not in a placental vessel, before injection [9].

The prepared syringes contained either 800 mcg misoprostol (four Misotac 200 mcg tablets) dissolved in $20 \mathrm{~mL}$ of normal saline or $20 \mathrm{~mL}$ of normal saline only. The cord was occluded by finger pressure around the catheter during injection, and was clamped with the catheter still in position after injection. If spontaneous delivery of the placenta did not occur, delivery by gentle cord traction was attempted at 15 and 30 minutes after injection. The time from umbilical vein injection to delivery of the placenta was recorded. Delivery of the placenta was assessed by clinical signs of placental separation and expulsion, as described by Rogers et al. [10]. The same procedures were followed in both treatment arms.

If placental delivery failed to occur within 30 minutes after the injection, or significant bleeding occurred, MROP was performed under general anaesthesia. The time and method of placental delivery (spontaneous by controlled cord traction or MROP) were recorded.

The volume of blood loss from the time of umbilical vein injection to delivery of the placenta was measured by placing a pad under the patient's buttocks. The pad weighed $45 \mathrm{~g}$ before use, and was weighed after delivery of the placenta using a dedicated electronic scale (up to $5 \mathrm{~kg})$. The blood loss was recorded in $\mathrm{mL}(1 \mathrm{~g}=1 \mathrm{~mL})$ [11].

Adverse effects after misoprostol administration such as shivering, fever, dizziness, vomiting, flushes, nausea, abdominal pain, and headache were recorded.

\section{Follow-up}

All women in both treatment arms were followed up for 24 hours postpartum. Vital signs (blood pressure, pulse rate, temperature, and respiratory rate), uterine fundal height, abnormal vaginal bleeding, and abdominal pain were recorded. Tonics, analgesics, and antibiotics were prescribed before discharge if needed, according to the local hospital guidelines.

\section{Statistical analysis}

All data were analysed using the Statistical Package for Social Sciences (SPSS), version 18. Proportions were compared between groups using the $X^{2}$ test. Mean values were compared using the student's T-test. MannWhitney test was used to determine the median of blood loss vaginally. A $P$ value of $\leq 0.05$ was considered statistically significant.

\section{Results}

$\mathrm{RP}$ is a relatively rare condition that may occur without any risk factors. Fifty women were diagnosed with RP during the study period, of which 46 met the criteria for inclusion in the study. Twenty-three women were allocated to each of the misoprostol and saline groups. In one woman in the misoprostol group, the cord detached from the placenta after injection.

\section{Patient characteristics}

There were no significant differences between the misoprostol and saline groups in terms of mean age, parity, or gestational age. There were also no significant differences between the two groups in terms of risk factors for RP including history of dilatation and curettage, preterm labour, and history of RP (Table 1).

\section{Outcomes after umbilical vein injection}

After umbilical vein injection, the placenta was delivered in 21 of the 23 women in the misoprostol group, and in 16 of the 23 women in the saline group, which was not a significant difference between the two groups (Table 2).

The median volume of blood loss from the time of umbilical vein injection until delivery of the placenta was significantly less in the misoprostol group $(100 \mathrm{~mL})$ than in the saline group $(210 \mathrm{~mL})$ using Mann-Whitney test.The range of vaginal blood loss vaginally was 30$75 \mathrm{ml}$ while the rang time to delivery using controlled cord traction was (5-23 minutes) in the misoprostol group versus (7-30 minutes) in the normal saline group (Table 2).

The mean time from injection until delivery of the placenta was $12.61 \pm 6.479$ minutes in the misoprostol group and $13.17 \pm 10.152$ minutes in the saline group $(P=0.823)$.

\section{Adverse effects after umbilical vein injection of misoprostol}

One of the 23 women who received misoprostol developed shivering that was attributed to misoprostol injection.

\section{Discussion}

\section{Delivery of the placenta}

The placenta was delivered after umbilical vein injection in $91.3 \%$ of the women who received misoprostol. The Cochrane review of umbilical vein injection for the treatment of RP found that injection of a prostaglandin solution resulted in a significant reduction in the rate of MROP compared with injection of saline solution, but did not result in differences in the volume of vaginal blood loss or adverse effects. However, the review was based on only two small trials including a total of 51 women, and both trials had low methodological quality [7]. 
Table 1 Demographic characteristics and risk factors for retained placenta

\begin{tabular}{llc}
\hline Characters and risk factors & Groups $(\boldsymbol{n}=\mathbf{2 3}$, in each group) & Mean \pm SD \\
\hline Age (years) & Mesoprostol group & $24.52 \pm 5.169$ \\
& Normal saline group & $25.83 \pm 4.668$ \\
Parity & Mesoprostol group & $1.30 \pm 1.222$ \\
& Normal saline group & $2.00 \pm 0.953$ \\
G. age (weeks) & Mesoprostol group & $37.22 \pm 2.876$ \\
& Normal saline group & $37.61 \pm 1.373$ \\
History of dilatation and curettage & Mesoprostol group & $4(17.4 \%)$ \\
& Normal saline group & $5(21.7 \%)$ \\
History of preterm labour & Mesoprostol group & $4(17.4 \%)$ \\
& Normal saline group & $1(4.3 \%)$ \\
History of retained placenta & Mesoprostol group & $1(4.3 \%)$ \\
& Normal saline group & $0(0 \%)$ \\
\hline
\end{tabular}

${ }^{*} T$-Test, ${ }^{*} X^{2}$ test.

Misoprostol is an analogue of prostaglandin E1 that interacts with specific receptors on myometrial cells, initiating a cascade of events including a change in calcium concentration that initiates myometrial contraction, and softening of the cervix, leading to expulsion of the uterine contents [12].

Umbilical vein injection of misoprostol may result in local action of misoprostol at the base of the placenta. The results of this study are comparable with those of a previous study that concluded that misoprostol was an effective treatment for RP compared with normal saline [4]. However, there was no significant difference in the rate of delivery of the placenta between the misoprostol and saline groups in this study, which may be due to the small sample size.

\section{Volume of blood loss}

There was a significant difference in the median volume of vaginal blood loss after umbilical vein injection between the misoprostol group and the saline group. This finding differed from those of Bider et al. [13], who reported a mean volume of blood loss of $210 \mathrm{~mL}$ in the prostaglandin group and $231 \mathrm{~mL}$ in the saline group $(\mathrm{p}=0.7)$. This difference may be due to the smaller sample size of their study $(\mathrm{n}=17)$ and the different uterotonic drug used (a prostaglandin F2 alpha analogue).

\section{Time to delivery of the placenta}

The mean time from umbilical vein injection until separation of the placenta was shorter in the misoprostol group $(13.63 \pm 5.29$ minutes) than in the saline group (18.93 \pm 5.89 minutes), but this was not a significant difference between the two groups. Rogers et al. reported no significant difference in the time to delivery of the placenta between the misoprostol and normal saline groups [14].

Harara et al. reported that the time to delivery of the placenta was significantly shorter in the misoprostol group $(7.0 \pm 2.2$ minutes). This may be because they compared misoprostol with two other uterotonic drugs (ergometrine and oxytocin) rather than with normal saline as in the current study [8].

\section{Adverse effects of misoprostol}

Only 1 of the 23 women who received misoprostol developed shivering. Bider et al. reported that 1 of 10 women experienced adverse effects (fever and shivering) after administration of a prostaglandin F2 alpha analogue [14].

\section{Limitations}

Although this study had significant findings in terms of delivery of the placenta after umbilical vein injection, it had some limitations. The sample size was small because

Table 2 Comparisons of outcomes between the misoprostol and saline groups

\begin{tabular}{cccl}
\hline $\mathbf{P}$ value & Normal Saline group $(\boldsymbol{n}=\mathbf{2 3})$ & Misoprostol group $(\boldsymbol{n}=\mathbf{2 3})$ & Outcome \\
\hline${ }^{*} 0.135$ & $7(30.4)$ & $2(8.7 \%)$ & Need for manual removal of placenta \\
$<0.001+$ & 210 & 100 & Median of blood loss vaginally \\
& $100-500$ & $30-75$ & Range of blood loss vaginally (ml) \\
& $7-30$ & $5-23$ & Range time for placental separation after CCT(mint) \\
\hline
\end{tabular}


$\mathrm{RP}$ is a relatively rare obstetric complication. Larger trials conducted over longer periods of time will be required to obtain definitive results. This study was also prone to assessment bias, because the investigator who administered the umbilical vein injection was aware of the group allocation. However, the women were alternately allocated to the two groups, and were not previously known to the investigators.

\section{Conclusion}

Umbilical vein injection of misoprostol dissolved in normal saline resulted in a reduced rate of MROP under general anaesthesia compared with injection of normal saline only.

\section{Competing interests}

The authors declare that they have no competing interests.

\section{Authors' contributions}

SA contributed to the development of the trial protocol. SR drafted the manuscript and performed umbilical vein injection in all subjects. Both authors contributed to data analysis, interpretation of the results, and revisions of the manuscript, and approved the final manuscript.

\section{Acknowledgement}

The authors thank Professor Namir G Al-taweel at Hawler Medical University, College of Medicine, Department of Community Medicine who assisted in the data analysis. The authors also thank all the women who agreed to participate in this study.

\section{Author details}

'Department of Obstetrics and Gynaecology, Shaheed Dr.Khalid General Hospital, Erbil City, Iraq. ${ }^{2}$ Department of Obstetrics and Gynaecology, College of Medicine, Hawler Medical University, Erbil City, Iraq.

Received: 16 April 2013 Accepted: 16 January 2014

Published: 21 January 2014

\section{References}

1. Hidar S, Jennane TM, Bouguizane S, Lassoued L, Bibi M, Khairi H: The effect of placental removal method at cesarean delivery on perioperative hemorrhage: a randomized clinical trial ISRCTN 49779257. Eur J Obstet Gynecol Reprod Biol 2004, 117:179-182.

2. National Collaborating Centre for Women's and Children's Health (NCCWCH): Intrapartum Care. Care of healthy women and their babies during childbirth. London: RCOG Press; 2007.

3. Ely JW, Rijhsinghani A, Bowdler NC, Dawson JD: The association between manual removal of placenta and postpartum endometritis following vaginal delivery. Obstet Gynecol 1995, 86:1002-1006.

4. Deyer TW, Ashton-Miller JA, Van Baren PM, Pearlman MD: Myometrial contractile strain at uteroplacental separation during parturition. Am J Obstet Gynecol 2000, 183:156-159.

5. Carroli G, Belizan JM, Grant A, Gonzalez L, Campodonico L, Bergel E: Intraumbilical vein injection and retained placenta: evidence from a collaborative large randomized controlled trial. Br J Obstet Gynaecol 1998, 105:179-185.

6. Purwar MB: Practical recommendations for umbilical vein injection formanagement of retained placenta. In The WHO Reproductive Health Library, Volume 4. Edited by Gulmezoglu AM, Villar J. Geneva: World Health Organization; 2001.

7. Nardin JM, Weeks A, Carroli G: Umbilical vein injection for management of retained placenta. The Cochrane Library, 2012, Issue 2. John Wiley \& Sons, Ltd: The Cochrane Collaboration; 2012.

8. Weeks A, Alia G, Vernon G, Namayanja A, Gosakan R, Majeed T, Hart A, Jafri H, Nardin J, Carroli G, Fairlie F, Raashid Y, Mirembe F, Alfirevic Z: Umbilical vein oxytocin for the treatment of retained placenta (Release Study): a double-blind, randomised controlled trial. Lancet 2010, 375:141-147.
9. Pipingas A, Hofmeyr GJ, Sesel KR: Umbilical vessel oxytocin administration for retained placenta: in-vitro study of various infusion techniques. Am J Obstet Gynecol 1993, 168:793-795.

10. Rogers MS, Yuen PM, Wong S: Avoiding manual removal of placenta: evaluation of intra-umbilical injection of uterotonics using the Pipingas technique for management of adherent placenta. Acta Obestet Gynecol Scand 2007, 86:48-54.

11. Hoj L, Cardoso P, Nielsen BB, Hvidman L, Neelsen J, Aaby P: Effect of sublingual misoprostol on severe postpartum haemorrhage in aprimary health centerin Guiea-Bissau:randomised double blind clinical trial. BMJ 2005, 331:723.

12. Challis JRG, Lye SJ: Physiology and endocrinology of term and preterm labor. In Obstetrics: Normal and Problem Pregnancies. Edited by Gabbe SG, Niebyl JR, Simpson JL. New York: Churchill Livingstone; 2002. Fourth edition.

13. Harara R, Hanafy S, Zidan MS, Alberry M: Intraumbilical injection of three different uterotonics in the management of retained placenta. J Obstet Gynaecol Res 2011, 37:1203-1207.

14. Bider D, Dulitzky M, Goldenberg M, Lipitz S, Mashiach S: Intraumbilical vein injection of prostaglandin in retained placenta. Eur J Obstet Gynecol Reprod Biol 1996, 64:59-61.

doi:10.1186/1471-2393-14-37

Cite this article as: Rajab and Alalaf: Umbilical vein injection of misoprostol versus normal saline for the treatment of retained placenta: intrapartum placebo-controlled trial. BMC Pregnancy and Childbirth $201414: 37$

\section{Submit your next manuscript to BioMed Central and take full advantage of:}

- Convenient online submission

- Thorough peer review

- No space constraints or color figure charges

- Immediate publication on acceptance

- Inclusion in PubMed, CAS, Scopus and Google Scholar

- Research which is freely available for redistribution 